\title{
Clinical analysis of 50 Eastern Asian patients with primary pulmonary large-cell neuroendocrine carcinoma
}

This article was published in the following Dove Press journal:

OncoTargets and Therapy

26 May 2015

Number of times this article has been viewed

\author{
Xin-ke Zhangl,* \\ Tao Qin ${ }^{1}, *$ \\ Yin-duo Zeng',2,* \\ Yuan-yuan Zhao' \\ Xue Hou' \\ Wen-feng Fang' \\ Shao-dong Hong' \\ Ting Zhou' \\ Zhi-huang $\mathrm{Hu}^{\prime}$ \\ Yun-peng Yang' \\ Yu-xiang $\mathrm{Ma}^{\prime}$ \\ Cong Xue' \\ Yan Huang' \\ Hong-yun Zhao' \\ Li Zhang'
}

'Sun Yat-sen University Cancer Center, State Key Laboratory of Oncology in South China, Collaborative Innovation Center for Cancer Medicine, Guangzhou, People's Republic of China; ${ }^{2}$ Sun Yat-sen Memorial Hospital, Sun Yat-sen University, Guangzhou, People's Republic of China

*These authors contributed equally to this work
Background: To understand the clinicopathological features of patients with primary pulmonary large-cell neuroendocrine carcinoma (LCNEC), including the frequency of epidermal growth factor receptor (EGFR) mutation, and to explore prognostic factors.

Methods: We investigated a cohort of 50 individuals from our center database who were diagnosed with operable pulmonary LCNEC and treated in Sun Yat-sen University Cancer Center. Serum albumin (ALB) and neuron-specific enolase (NSE) were also collected. Survival curves were obtained with the Kaplan-Meier method, and the differences between groups in survival were tested by the log-rank test.

Results: The median age was 59 years (range, 40-80 years). Fourteen patients underwent mutational analysis of EGFR; of these, 12 had wild-type EGFR and the remaining two had EGFR mutations in exons. The median disease-free survival (DFS) of pulmonary LCNEC was 49.3 months and that of overall survival (OS) was not reached. DFS and OS were shorter for patients with decreased serum ALB than for patients with normal serum ALB $(P=0.003$ and $P=0.004$, respectively). Meanwhile, a high level of NSE was also significantly associated with short DFS and OS $(P=0.005$ and $P=0.000$, respectively). Multivariate analysis showed that decrease in serum ALB was an independent prognostic factor for OS $(P=0.046)$.

Conclusion: The frequency of EGFR mutation in LCNEC patients is low. Serum ALB and NSE levels are valuable prognostic factors for LCNEC patients.

Keywords: pulmonary large cell neuroendocrine carcinoma, ALB, NSE, EGFR, prognosis

\section{Introduction}

Pulmonary large-cell carcinoma is an uncommon type of non-small-cell lung carcinoma (NSCLC), accounting for approximately $3 \%-9 \%$ of all cases. ${ }^{1,2}$ It is poorly differentiated and has diverse morphological variants, such as basaloid, clear cell, pulmonary combined large-cell neuroendocrine, large-cell lung with rhabdoid phenotype, lymphoepithelioma-like, and large-cell neuroendocrine carcinomas (LCNECs). Regarding its pathological diagnosis, its morphological and histological characteristics differ from small cell carcinoma, and it shows no evidence of squamous carcinoma or adenocarcinoma according to the 2004 World Health Organization classification of pulmonary carcinomas. ${ }^{3}$ As shown in a previous study, LCNEC represents nearly $1.6 \%-3.1 \%$ of all pulmonary carcinomas and is poorly differentiated, with low incidence. These types of carcinomas commonly have aggressive behavior and an adverse prognosis. ${ }^{4}$

Although the mechanisms of some gene mutations and molecular distortions in pulmonary carcinoma are known, it is still necessary to create new therapeutic 
strategies to extend the survival rate. ${ }^{5}$ One study suggested that the clinical survival rate is poor for patients with LCNEC, including those diagnosed at an early stage. ${ }^{6}$ Additionally, two studies verified worse prognoses for patients with LCNEC, and the overall survival (OS) rate of 5 years was shown to be $15 \%-57 \% .^{7,8}$ A life table analysis of pulmonary large cell carcinoma revealed that the 5-year survival rate also decreased and varied between $12 \%-56 \%{ }^{9}$

Prior research has implied that the frequency of epidermal growth factor receptor (EGFR) mutations was linked to various factors such as smoking status, sex, ethnicity, and histological subtype of pulmonary carcinoma. ${ }^{10-12}$ EGFR mutation rates of $2 \%$ and $4 \%$ in large cell carcinomas have been documented, ${ }^{9,11}$ and these mutations were seen in $10 \%-20 \%$ of patients with NSCLC. ${ }^{12}$ Another study reported a mutation rate of $7.7 \%$ in LCNEC. ${ }^{13}$ Unfortunately, previous studies presented too little information regarding the rate in LCNEC. Thus, further research on the frequency of EGFR mutations is necessary for advancing clinical treatment.

In the past decades, researchers discovered that the treatment of EGFR-tyrosine kinase inhibitor (TKI) was valid for patients with NSCLC, especially for Asian patients with pulmonary adenocarcinoma and EGFR mutations located in exon 19 or $21 .{ }^{14}$ Better clinical prognosis has been associated with EGFR mutations in NSCLC patients sensitive to TKI, indicating that EGFR should be considered a useful predictor of survival time. ${ }^{15}$ In the 2014 National Comprehensive Cancer Network guidelines, EGFR-TKIs, including gefitinib, erlotinib, and apatinib, were proposed as the first line of therapy for NSCLC; this therapy improved conditions in $70 \%$ of patients with pulmonary carcinomas and EGFR mutations. ${ }^{16}$ Early-stage diagnosis, female sex, good Eastern Cooperative Oncology Group performance status $(0,1$, or 2$)$, and a weight loss of less than $5 \%$ were identified as strong prognostic indicators for OS in patients with NSCLC. ${ }^{17}$ The prognostic indicators of LCNEC could not be determined. However, a previous study found that low albumin (ALB) levels predicted poor prognosis in pulmonary lymphoepithelioma-like carcinoma, ${ }^{18}$ and no studies identified the prognostic markers for LCNEC, including serum ALB and neuron-specific enolase (NSE) levels. This study was performed to analyze the relationships between clinicopathological characteristics and EGFR mutations and to investigate the prognostic factors impacting OS in primary pulmonary LCNEC.

\section{Materials and methods Ethics}

This was an observational and retrospective research study that was granted approval by the Institute Research Medical Ethics Committee of Sun Yat-sen University Cancer Center.

\section{Patients}

Fifty patients diagnosed with pulmonary LCNEC were recruited for this study. All were recruited from the Sun Yat-sen University Cancer Center, Guangzhou, People's Republic of China, from January 2000 to January 2012. Pulmonary LCNEC was verified by a pathological diagnosis according to the 2004 World Health Organization classification of pulmonary tumors. The patients were chosen according to the following requirements: pathologically diagnosed with LCNEC, no chemotherapy or radiation treatment before surgical resection, no other primary tumors, and regular follow-up.

Case records were used to retrieve clinical information such as sex, age at diagnosis, smoking status, pathological TNM stage, tumor size, treatment strategy, and several blood biomarkers consisting of NSE, ALB, and others. EGFR mutation status was also included. Additionally, data on OS (ie, the date of surgery to the date of death from any cause, or to the last follow-up date if the patient was alive) and disease-free survival (DFS; ie, the length of time from the date of surgery on the primary tumor to local, regional, or distant recurrence or death from any cause) were gathered for the enrolled patients.

\section{Selection of cutoff value for serum NSE level}

Calculating 1 - specificity and corresponding sensitivity depending on variable cutoffs generates a curve called a receiver operating characteristic (ROC) curve. The ideal cutoff value could be identified with ROC curve analysis by the point $(0.0,1.0),{ }^{19,20}$ for the serum NSE levels, plotting the sensitivity and specificity for each clinical factors, and formatting different ROC curves. The value chosen as the cutoff value was closest to the point with both the greatest sensitivity and specificity. The values less than or equal to the cutoff value were regarded as decreased serum NSE levels, and values greater than the cutoff value were thought of as increased levels.

\section{Statistical analysis}

Statistical analysis was performed using SPSS software, version 16.0 (Chicago, IL, USA). Correlations between 
EGFR mutation frequency and the clinicopathological parameters of patients with LCNEC were assessed using the chi-square test. An ROC curve was used to identify the cutoff value for serum NSE. Survival curves for the groups of decreased and normal serum ALB levels and decreased and increased serum NSE levels were plotted using the Kaplan-Meier analysis, and the discrepancies between groups regarding survival rates were calculated using the log-rank test. Univariate and multivariate analyses were performed using the Cox regression hazards model to identify the impact of different prognostic indicators on survival. Alpha values of $P<0.05$ were considered to be statistically significant differences.

\section{Results}

\section{Patients' characteristics}

The clinical information of 50 patients diagnosed with pulmonary LCNEC is detailed in Table 1 . The patients in this study included 47 (94\%) male cases and three (6\%) female cases. The median age at diagnosis was 59 years (range, 40-80 years). Of all the patients, 35 (70\%) had a smoking history and 15 (30\%) had never smoked. The tumor median size was $4.25 \mathrm{~cm}$ and varied between $0.5-16.0$ $\mathrm{cm}$. Forty patients were diagnosed at the limited stage $(22$ cases with grade IA and IB, 18 cases with grade IIA and

Table I Clinical characteristics of 50 patients with LCNEC

\begin{tabular}{|c|c|c|}
\hline Variables & $\mathbf{n}$ & $\%$ \\
\hline \multicolumn{3}{|l|}{ Sex } \\
\hline Male & 47 & 94 \\
\hline Female & 3 & 6 \\
\hline \multicolumn{3}{|c|}{ Age at surgery (years) } \\
\hline$\leq 60$ & 27 & 54 \\
\hline$>60$ & 23 & 46 \\
\hline \multicolumn{3}{|l|}{ Smoking status } \\
\hline Nonsmoker & 15 & 30 \\
\hline Smoker & 35 & 70 \\
\hline \multicolumn{3}{|l|}{ T classification } \\
\hline TI-T2 & 33 & 66 \\
\hline T3-T4 & 17 & 34 \\
\hline \multicolumn{3}{|l|}{$\mathrm{N}$ classification } \\
\hline No & 34 & 68 \\
\hline $\mathrm{NI}-\mathrm{N} 3$ & 16 & 32 \\
\hline \multicolumn{3}{|l|}{ Clinical stage } \\
\hline I-II & 40 & 80 \\
\hline III & 10 & 20 \\
\hline \multicolumn{3}{|c|}{ Tumor size $(\mathrm{cm})$} \\
\hline$\leq 3$ & 19 & 38 \\
\hline$>3$ & 31 & 62 \\
\hline
\end{tabular}

Abbreviation: LCNEC, large-cell neuroendocrine carcinoma.
IIB), 10 cases were in the extensive stage (grade IIIA and IIIB). The median length of DFS in these patients with pulmonary LCNEC was 49.3 months; that of OS was not reached (Figure 1). According to the ROC curve analysis, the value of $34.89 \mathrm{U} / \mathrm{mL}$ was selected as the cutoff value for serum NSE levels (Figure 2), by which 16 cases (32\%) had increased NSE serum levels $(>34.89 \mathrm{U} / \mathrm{mL})$ and 34 cases $(68 \%)$ had decreased NSE levels $(\leq 34.89 \mathrm{U} / \mathrm{mL})$. The low value of normal range of $35 \mathrm{~g} / \mathrm{L}$ was considered as the cutoff value of serum ALB levels, by which 20 cases $(40 \%)$ had decreased ALB levels ( $\leq 35.0 \mathrm{~g} / \mathrm{L})$ and 30 cases $(60 \%)$ had normal levels $(>35.0 \mathrm{~g} / \mathrm{L})$.

\section{Analysis of EGFR mutations in patients with the detection of EGFR mutation}

Of all the patients, only 14 cases were selected to examine the frequency of EGFR mutations; the results included 12 cases with wild-type EGFR and two with mutations located in exons 18,19 , or 15 . The EGFR mutation rate was $14.3 \%$ (2/14). One case had EGFR mutations located on exons 18 and 15 , and another had mutations on exons 19 and 15. Twelve male cases had no EGFR mutations $(0 \%, 0 / 12)$, and two female cases had EGFR mutations (100\%, 2/2). In patients with no smoking history, the EGFR mutation incidence was $40 \%(2 / 5)$ and that of patients with a smoking history was $0 \%(0 / 9)$.

\section{Selection of cutoff value for serum NSE and ALB levels}

According to the ROC curve analysis, the survival status had the point closest to the point $(0.0,1.0)$. On the basis of this outcome, we selected a serum NSE level of $34.89 \mathrm{U} / \mathrm{mL}$ identified by the survival status as the suitable cutoff value for survival analysis. Sixteen cases (32\%) had increased NSE serum levels $(>34.89 \mathrm{U} / \mathrm{mL})$ and 34 cases $(68 \%)$ had decreased NSE levels $(\leq 34.89 \mathrm{U} / \mathrm{mL})$. The low value of normal range of $35 \mathrm{~g} / \mathrm{L}$ was considered as the cutoff value of serum ALB levels, twenty cases (40\%) had decreased ALB levels $(\leq 35.0 \mathrm{~g} / \mathrm{L})$ and 30 cases $(60 \%)$ had normal levels $(>35.0 \mathrm{~g} / \mathrm{L})$.

\section{Analysis of the relationship between serum NSE, ALB levels, and clinical characteristics in patients with LCNEC}

The results also showed no significant relationship between serum NSE, ALB levels, and clinical features including age at surgery, sex, smoking status, T classification, tumor size, 

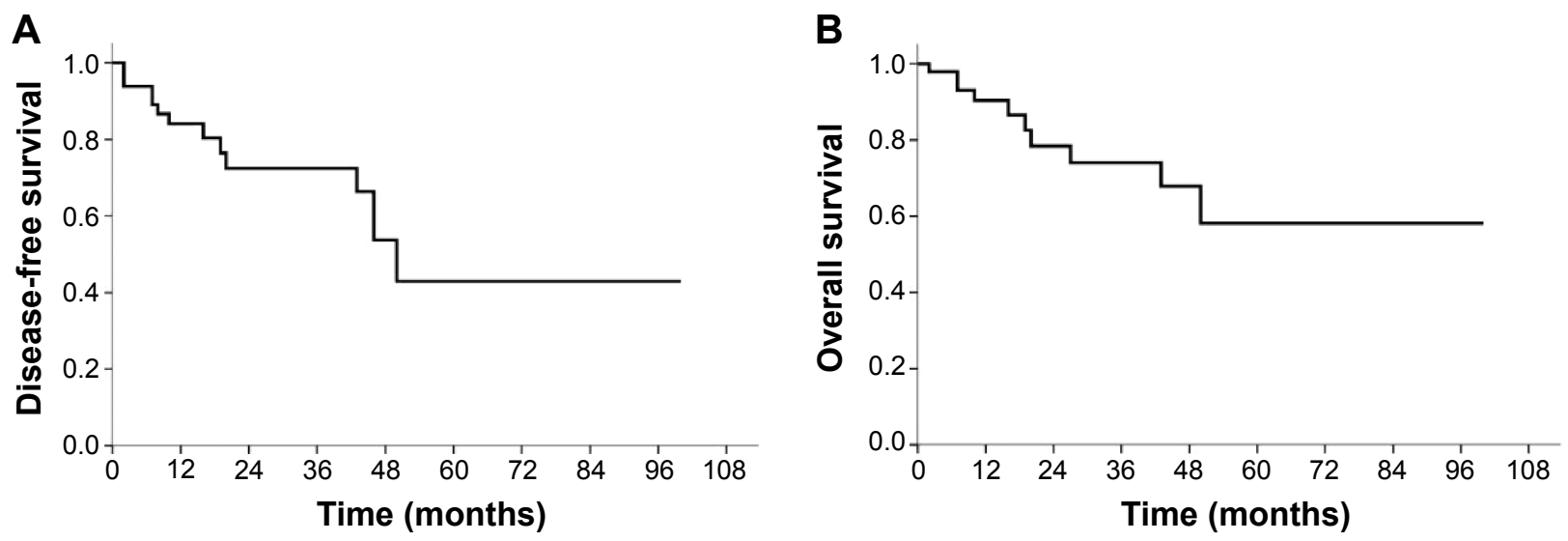

Figure I Survival curves of 50 patients with LCNEC.

Notes: (A) Disease-free survival. (B) Overall survival.

Abbreviation: LCNEC, large-cell neuroendocrine carcinoma.

$\mathrm{N}$ classification, and clinical stage ( $P>0.05$, Tables 2 and 3$)$, and a strong tendency toward statistical significance between serum NSE levels and each of tumor size and $\mathrm{N}$ classification ( $P=0.068$ and $P=0.061$, respectively; Table 2 ).

\section{Univariate and multivariate analyses of the relationship between survival status and the clinicopathological features of LCNEC}

The univariate analysis revealed a significant association between survival status and clinicopathological indicators,

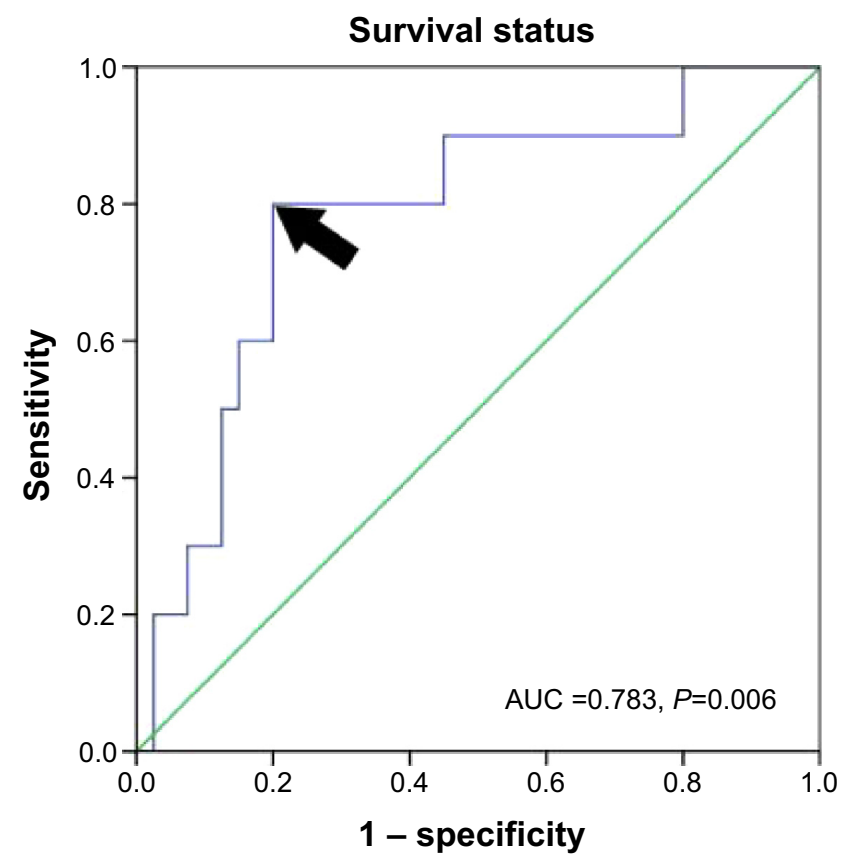

Figure 2 The selection of cutoff value of serum NSE levels by ROC curve. Note: The arrow indicates the point of both maximum sensitivity and specificity. Abbreviations: AUC, area under the curve; NSE, neuron-specific enolase; ROC, receiver operating characteristic. including N classification, ALB, and NSE serum levels $(P<0.05$, Table 4$)$. The Kaplan-Meier method also demonstrated that decreased ALB levels were significantly linked to adverse DFS $(P=0.003$, Figure $3 \mathrm{~A})$ and $\mathrm{OS}(P=0.004$, Figure 3B). Increased NSE levels were inversely associated with poor DFS $(P=0.005$, Figure $3 \mathrm{C})$ and OS $(P=0.000$, Figure 3D). The Cox regression model analysis also showed that worse OS was significantly correlated with decreased ALB levels (hazard ratio $=0.166,95 \%$ confidence interval $=0.042-0.661 ; P=0.011)$ and increased NSE levels (hazard ratio $=10.429,95 \%$ confidence interval $=2.208$ 49.249; $P=0.003$ ) (Table 4). Lymph node metastasis status was also inversely linked with unfavorable OS in patients with LCNEC $(P=0.017)$. The multivariate analysis demonstrated that decreased serum ALB was an independent prognostic biomarker for OS $(P=0.046)$, and increased serum NSE had a tendency toward statistical significance for OS $(P=0.062)$ (Table 4).

\section{Discussion}

A low incidence of EGFR mutations was demonstrated in this study. In the 50 patients with LCNEC, the mutations most often occurred in the females and nonsmokers. Patients with decreased ALB serum levels and high NSE serum levels before surgical resection had adverse DFS and OS.

Some studies have indicated that the survival rate for was virtually shorter for LCNEC compared to other types of NSCLC, but the survival period was similar to that of smallcell lung cancer (SCLC). ${ }^{8,21,22}$ Approximately $2 \%-10 \%$ of patients with SCLC at the early or advanced stage survived 5 years after diagnosis. ${ }^{23}$ Several studies have reported that 5 -year OS fluctuated between $15 \%$ and $57 \%$ for patients with lung LCNEC. ${ }^{22,24}$ The present study found that the 5-year 
Table 2 Correlations between serum NSE levels and clinicopathological features in patients with primary pulmonary LCNEC

\begin{tabular}{|c|c|c|c|c|}
\hline & \multirow[t]{2}{*}{ All cases, $n$} & \multicolumn{3}{|l|}{ Serum NSE } \\
\hline & & Decreased levels, $\mathbf{n}(\%)$ & Increased levels, n (\%) & $P$-value* \\
\hline Sex & & & & 0.959 \\
\hline Male & 47 & 32 (68.1\%) & 15 (31.9\%) & \\
\hline Female & 3 & $2(66.7 \%)$ & I (33.3\%) & \\
\hline Age at surgery (years) & & & & 0.827 \\
\hline$\leq 60$ & 27 & $18(66.7 \%)$ & 9 (33.3\%) & \\
\hline$>60$ & 23 & $16(69.6 \%)$ & 7 (30.4\%) & \\
\hline Smoking status & & & & 0.234 \\
\hline Nonsmoker & 15 & $12(80.0 \%)$ & $3(20.0 \%)$ & \\
\hline Smoker & 35 & $22(62.9 \%)$ & $13(37.1 \%)$ & \\
\hline T classification & & & & 0.357 \\
\hline TI-T2 & 33 & $21(63.6 \%)$ & $12(36.4 \%)$ & \\
\hline T3-T4 & 17 & $13(76.5 \%)$ & $4(23.5 \%)$ & \\
\hline $\mathrm{N}$ classification & & & & 0.061 \\
\hline No & 34 & $26(76.5 \%)$ & $8(23.5 \%)$ & \\
\hline $\mathrm{NI}-\mathrm{N} 3$ & 16 & $8(50.0 \%)$ & $8(50.0 \%)$ & \\
\hline Clinical stage & & & & 0.880 \\
\hline I-II & 40 & 27 (67.5\%) & $13(32.5 \%)$ & \\
\hline III & 10 & $7(70.0 \%)$ & $3(30.0 \%)$ & \\
\hline Tumor size $(\mathrm{cm})$ & & & & 0.068 \\
\hline$\leq 3$ & 19 & $10(52.6 \%)$ & $9(47.4 \%)$ & \\
\hline$>3$ & 31 & $24(77.4 \%)$ & $7(22.6 \%)$ & \\
\hline
\end{tabular}

Note: *Chi-square test.

Abbreviations: LCNEC, large-cell neuroendocrine carcinoma; NSE, neuron-specific enolase.

OS rate for patients with pulmonary LCNEC was $58 \%$. However, compared to previous studies of limited-stage SCLC, a much longer survival time in patients with LCNEC was shown, which was similar to the results of a prior study on lung LCNEC.
The existence of prognostic factors of LCNEC has been proven in several previous studies. ${ }^{8,25,26}$ EGFR mutation was shown to be a good predictive indicator for patients with NSCLC who achieved disease remission after treatment with EGFR-TKI. ${ }^{27}$ This mutation frequency in LCNEC was

Table 3 Correlation between serum ALB levels and clinicopathological features in patients with primary pulmonary LCNEC

\begin{tabular}{|c|c|c|c|c|}
\hline & \multirow[t]{2}{*}{ All cases, $\mathbf{n}$} & \multicolumn{3}{|l|}{ Serum ALB } \\
\hline & & Decreased levels, n (\%) & Normal levels, n (\%) & $P$-value* \\
\hline Sex & & & & 0.145 \\
\hline Male & 47 & $20(42.6 \%)$ & 27 (57.4\%) & \\
\hline Female & 3 & $0(0.0 \%)$ & $3(100.0 \%)$ & \\
\hline Age at surgery (years) & & & & 0.487 \\
\hline$\leq 60$ & 27 & 12 (44.4\%) & I 5 (55.6\%) & \\
\hline$>60$ & 23 & $8(34.8 \%)$ & $15(65.2 \%)$ & \\
\hline Smoking status & & & & 0.208 \\
\hline Nonsmoker & 15 & $4(26.7 \%)$ & II (73.3\%) & \\
\hline Smoker & 35 & $16(45.7 \%)$ & $19(54.3 \%)$ & \\
\hline T classification & & & & 0.626 \\
\hline TI-T2 & 33 & 14 (42.4\%) & $19(57.6 \%)$ & \\
\hline T3-T4 & 17 & $6(35.3 \%)$ & I I (64.7\%) & \\
\hline $\mathrm{N}$ classification & & & & 0.322 \\
\hline No & 34 & 12 (35.3\%) & $22(64.7 \%)$ & \\
\hline NI-N3 & 16 & $8(50.0 \%)$ & $8(50.0 \%)$ & \\
\hline Clinical stage & & & & 1.000 \\
\hline I-II & 40 & I 6 (40.0\%) & $24(60.0 \%)$ & \\
\hline III & 10 & $4(40.0 \%)$ & $6(60.0 \%)$ & \\
\hline Tumor size $(\mathrm{cm})$ & & & & 0.405 \\
\hline$\leq 3$ & 19 & $9(47.4 \%)$ & $10(52.6 \%)$ & \\
\hline$>3$ & 31 & I I (35.5\%) & $20(64.5 \%)$ & \\
\hline
\end{tabular}

Note: *Chi-square test.

Abbreviations: ALB, albumin; LCNEC, large-cell neuroendocrine carcinoma. 
Table 4 Univariate and multivariate analyses of different prognostic variables for overall survival in patients with primary pulmonary LCNEC

\begin{tabular}{|c|c|c|c|c|c|}
\hline \multirow[t]{2}{*}{ Variable } & \multicolumn{3}{|c|}{ Univariate analysis* } & \multicolumn{2}{|l|}{ Multivariate analysis* } \\
\hline & All cases, $\mathbf{n}$ & Hazard ratio $(95 \% \mathrm{Cl})$ & $P$-value & Hazard ratio $(95 \% \mathrm{Cl})$ & $P$-value \\
\hline Sex & & & 0.983 & & \\
\hline Male & 47 & Reference & & & \\
\hline Female & 3 & $0.978(0.12 \mathrm{I}-7.926)$ & & & \\
\hline Age at surgery (years) & & & 0.860 & & \\
\hline$\leq 60$ & 27 & Reference & & & \\
\hline$>60$ & 23 & I.II9 (0.323-3.872) & & & \\
\hline Smoking status & & & 0.869 & & \\
\hline Nonsmoker & 15 & Reference & & & \\
\hline Smoker & 35 & I.I2I (0.289-4.35I) & & & \\
\hline Tumor size $(\mathrm{cm})$ & & & 0.988 & & \\
\hline$\leq 3$ & 19 & Reference & & & \\
\hline$>3$ & 31 & $0.990(0.279-3.516)$ & & & \\
\hline T classification & & & 0.431 & & \\
\hline TI-T2 & 33 & Reference & & & \\
\hline T3-T4 & 17 & $1.670(0.467-5.972)$ & & & \\
\hline \multicolumn{6}{|l|}{$\mathrm{N}$ classification } \\
\hline No & 34 & Reference & 0.017 & $3.626(0.793-16.585)$ & 0.097 \\
\hline NI-N3 & 16 & $5.522(1.362-22.397)$ & & & \\
\hline ALB & & & 0.011 & $0.211(0.046-0.976)$ & 0.046 \\
\hline$\leq 35.0 \mathrm{~g} / \mathrm{L}$ & 20 & Reference & & & \\
\hline$>35.0 \mathrm{~g} / \mathrm{L}$ & 30 & $0.166(0.042-0.661)$ & & & \\
\hline NSE & & & 0.003 & $4.795(0.922-24.944)$ & 0.062 \\
\hline$\leq 34.89 \mathrm{U} / \mathrm{L}$ & 34 & Reference & & & \\
\hline$>34.89 \mathrm{U} / \mathrm{L}$ & 16 & $10.429(2.208-49.249)$ & & & \\
\hline
\end{tabular}

Note: *Cox regression model.

Abbreviations: ALB, albumin; Cl, confidence interval; LCNEC, large-cell neuroendocrine carcinoma; NSE, neuron-specific enolase.

entirely in accordance with that of patients with poorly differentiated adenocarcinoma. ${ }^{28}$ One study reported an EGFR mutations rate of $2 \%$ in large-cell lung carcinomas with glandular differentiation. ${ }^{9}$ Another study found a frequency of $9.1 \%$ in lymphoepithelioma-like carcinoma as a subclassification of large cell carcinoma. ${ }^{29}$ Therefore, previous studies on LCNEC were limited. Most were case reports for Western populations, with few studies on EGFR mutations in Asian patients with LCNEC. The present study examined these mutations in 14 patients, including two cases with mutation-type EGFR and 12 cases with wild-type EGFR. The mutation rate was consistent with the results of prior studies. Nevertheless, LCNEC incidence was low, and EGFR mutations could not be detected in all patients. Therefore, the association between mutation status and survival time for the 14 patients tested was not investigated. The number of patients with the mutations was too small, and the statistical analysis was impossible to perform in this retrospective study. If more patients with LCNEC and EGFR mutations had been recruited in the study, the correlation could have been more precisely discussed.
Apart from molecular types, the prognostic significance of lymph node metastasis status for LCNEC was identical with that of other types of lung cancers. In the present study, absent lymph node metastasis predicted a better prognosis in patients with LCNEC. However, it did not serve as an independent prognostic predictor, perhaps for two reasons. First, the number of cases studied was small because the LCNEC was an exclusive diagnosis. Second, the effects of other prognostic factors were superior to lymph node metastasis status for OS in the small sample study.

A study reported that NSCLC with neuroendocrine differentiation had the sensitivity of anticancer treatment, ${ }^{30}$ whereas another study demonstrated that high serum NSE levels predicted resistance to EGFR-TKIs in patients with advanced-stage NSCLC. ${ }^{31}$ Easily measurable serum markers NSE and ALB also served as promising prognostic factors. A previous study reported that serum NSE levels might be regarded to represent the prognostic index in pulmonary neuroendocrine tumors. ${ }^{32}$ In our study, the results of univariate analysis indicated that patients with high NSE serum levels had worse clinical prognoses. Moreover, a strong tendency toward statistical significance was demonstrated 

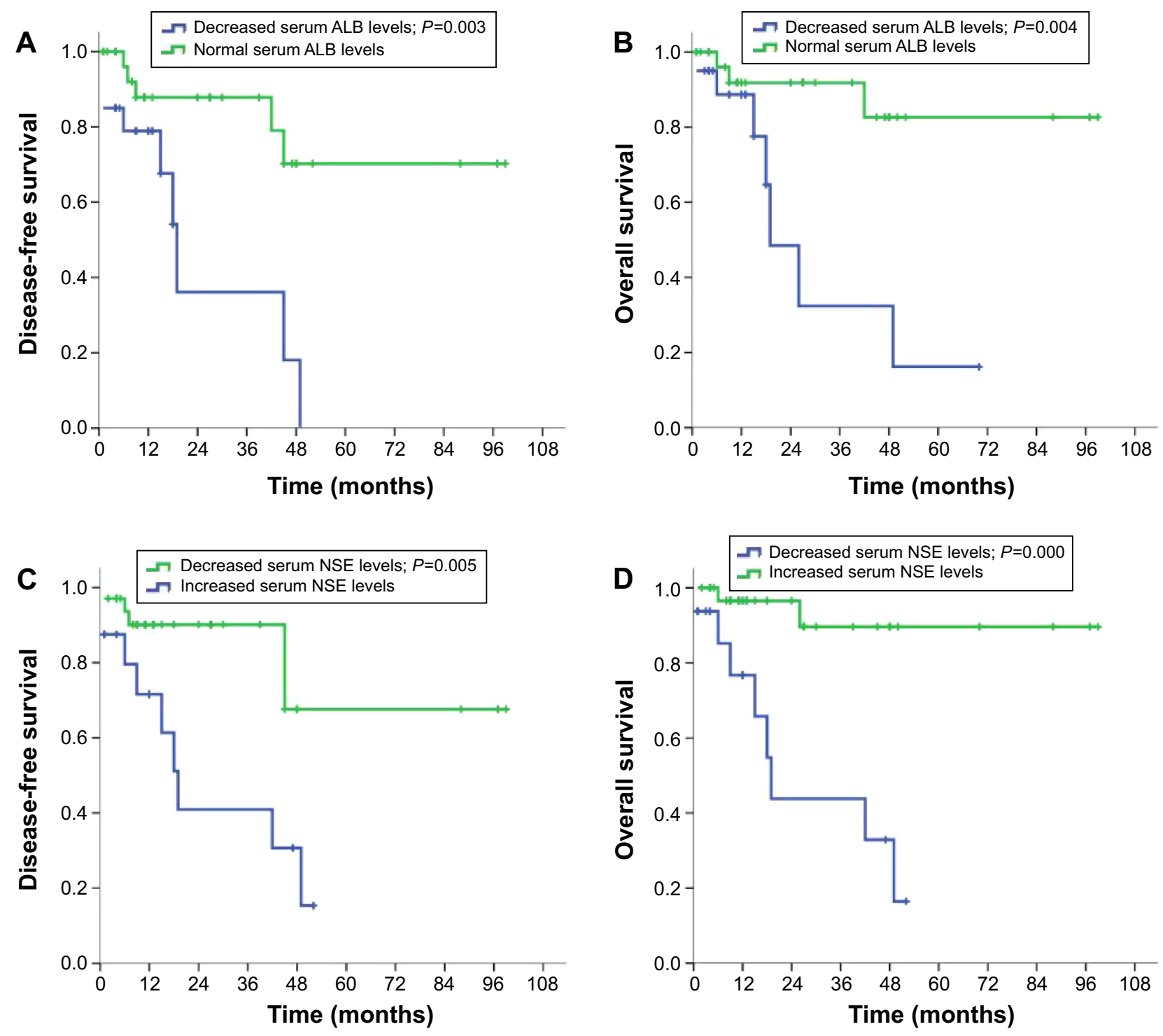

Figure 3 Disease-free survival and overall survival by different levels of ALB and NSE.

Notes: (A) DFS and (B) OS by different levels of ALB; (C) DFS and (D) OS by different levels of NSE.

Abbreviations: ALB, albumin; NSE, neuron-specific enolase; DFS, disease-free survival; OS, overall survival.

between tumor size, the status of lymph node metastasis, and serum NSE levels. This finding suggested that tumor size and tumor metastasis might have a certain degree of association with serum NSE levels. This finding was partially consistent with the finding that serum NSE levels depended on the tumor size and clinical stage in NSCLC. ${ }^{33}$ Another report showed that serum NSE levels could reflect the status of tumor burden and might be increased after chemotherapy. ${ }^{34}$ Therefore, we speculated that serum NSE levels seemed to be associated with the following two factors: first, the serum release of LCNEC cells with NSE was due to rapid tumor growth; and second, tumor aggressiveness and metastasis led to the destruction of LCNEC cells containing NSE. ${ }^{32}$
Additionally, serum ALB acted as an important part in hepatocellular cancer prognostic models and was significantly associated with prognosis of pancreatic cancer. ${ }^{35,36}$ Univariate analysis demonstrated that decreased serum ALB level was significantly associated with unfavorable prognosis for patients with LCNEC. This was in agreement with prior studies. Serum ALB levels impartially reflected the nutrition status of patients and the capacity to combine with therapeutic agents. Decreased ALB levels represented that these patients had poor nutritional status and low concentration of therapeutic agents due to worse binding capacity. Multivariate analysis revealed that serum ALB level was an independent prognostic factor and serum NSE level was not, indicating that the impact of serum ALB levels were superior to that of 
serum NSE levels for the prognosis of LCNEC in this study. In other words, the routine anticancer therapy strategies were on the basis of normal serum ALB levels in clinical practice for these patients.

\section{Conclusion}

LCNEC was a highly malignant and aggressive carcinoma. EGFR mutations were more common in nonsmokers and women with LCNEC. Elevated ALB serum level was an independent prognostic indicator. Although the frequency of EGFR mutations was lower in patients with LCNEC than in patients with NSCLC, it is still necessary to demonstrate the association between EGFR mutations and the development and progression of LCNEC in future studies, as well as to explore the correlation between the molecular biomarkers and prognosis for patients with LCNEC.

\section{Acknowledgments}

This research was supported by funds from the Guangdong Province Natural Science Fund (S2013010016564). The funders had no role in study design, data collection and analysis, decision to publish, or preparation of the manuscript.

\section{Author contributions}

All authors made substantial contributions to data generation and analysis, drafting or critical revision of the manuscript, and approval for the final version to be published.

\section{Disclosure}

The authors report no conflicts of interest in this work.

\section{References}

1. Iwasaki Y. [Large cell carcinoma]. Nihon Rinsho. 2000;58(5):1127-1131. Japanese.

2. Reynolds T. "User-friendly" cancer statistics review features new format. J Natl Cancer Inst. 1992;84(19):1470-1471.

3. Rossi G, Mengoli MC, Cavazza A, et al. Large cell carcinoma of the lung: clinically oriented classification integrating immunohistochemistry and molecular biology. Virchows Arch. 2014;464(1):61-68.

4. Travis WD, Linnoila RI, Tsokos MG, et al. Neuroendocrine tumors of the lung with proposed criteria for large-cell neuroendocrine carcinoma. An ultrastructural, immunohistochemical, and flow cytometric study of 35 cases. Am J Surg Pathol. 1991;15(6):529-553.

5. Gazdar AF. The molecular and cellular basis of human lung cancer. Anticancer Res. 1994;14(1B):261-267.

6. Iyoda A, Jiang SX, Travis WD, et al. Clinicopathological features and the impact of the new TNM classification of malignant tumors in patients with pulmonary large cell neuroendocrine carcinoma. Mol Clin Oncol. 2013; 1(3):437-443.

7. Iyoda A, Hiroshima K, Nakatani Y, Fujisawa T. Pulmonary large cell neuroendocrine carcinoma: its place in the spectrum of pulmonary carcinoma. Ann Thorac Surg. 2007;84(2):702-707.

8. Asamura H, Kameya T, Matsuno Y, et al. Neuroendocrine neoplasms of the lung: a prognostic spectrum. J Clin Oncol. 2006;24(1):70-76.
9. Rekhtman N, Tafe LJ, Chaft JE, et al. Distinct profile of driver mutations and clinical features in immunomarker-defined subsets of pulmonary large-cell carcinoma. Mod Pathol. 2013;26(4):511-522.

10. Murray S, Karavasilis V, Bobos M, et al. Molecular predictors of response to tyrosine kinase inhibitors in patients with non-small-cell lung cancer. J Exp Clin Cancer Res. 2012;31:77.

11. Sugio K, Uramoto H, Ono K, et al. Mutations within the tyrosine kinase domain of EGFR gene specifically occur in lung adenocarcinoma patients with a low exposure of tobacco smoking. Br J Cancer. 2006;94(6):896-903.

12. Soria JC, Mok TS, Cappuzzo F, Jänne PA. EGFR-mutated oncogeneaddicted non-small cell lung cancer: current trends and future prospects. Cancer Treat Rev. 2012;38(5):416-430.

13. Iyoda A, Travis WD, Sarkaria IS, et al. Expression profiling and identification of potential molecular targets for therapy in pulmonary large-cell neuroendocrine carcinoma. Exp Ther Med. 2011;2(6): 1041-1045.

14. Takano T, Fukui T, Ohe Y, et al. EGFR mutations predict survival benefit from gefitinib in patients with advanced lung adenocarcinoma: a historical comparison of patients treated before and after gefitinib approval in Japan. J Clin Oncol. 2008;26(34):5589-5595.

15. Eberhard DA, Johnson BE, Amler LC, et al. Mutations in the epidermal growth factor receptor and in KRAS are predictive and prognostic indicators in patients with non-small-cell lung cancer treated with chemotherapy alone and in combination with erlotinib. J Clin Oncol. 2005; 23(25):5900-5909.

16. Rosell R, Moran T, Queralt C, et al; Spanish Lung Cancer Group. Screening for epidermal growth factor receptor mutations in lung cancer. N Engl J Med. 2009;361(10):958-967.

17. Finkelstein DM, Ettinger DS, Ruckdeschel JC. Long-term survivors in metastatic non-small-cell lung cancer: an Eastern Cooperative Oncology Group Study. J Clin Oncol. 1986;4(5):702-709.

18. Liang Y, Wang L, Zhu Y, et al. Primary pulmonary lymphoepitheliomalike carcinoma: fifty-two patients with long-term follow-up. Cancer. 2012; 118(19):4748-4758.

19. Greiner M, Pfeiffer D, Smith RD. Principles and practical application of the receiver-operating characteristic analysis for diagnostic tests. Prev Vet Med. 2000;45(1-2):23-41.

20. Cai MY, Zhang B, He WP, et al. Decreased expression of PinX1 protein is correlated with tumor development and is a new independent poor prognostic factor in ovarian carcinoma. Cancer Sci. 2010;101(6): $1543-1549$.

21. Takei H, Asamura H, Maeshima A, et al. Large cell neuroendocrine carcinoma of the lung: a clinicopathologic study of eighty-seven cases. J Thorac Cardiovasc Surg. 2002;124(2):285-292.

22. Iyoda A, Hiroshima K, Toyozaki T, Haga Y, Fujisawa T, Ohwada H. Clinical characterization of pulmonary large cell neuroendocrine carcinoma and large cell carcinoma with neuroendocrine morphology. Cancer. 2001;91(11):1992-2000.

23. Chua YJ, Steer C, Yip D. Recent advances in management of small-cell lung cancer. Cancer Treat Rev. 2004;30(6):521-543.

24. Paci M, Cavazza A, Annessi V, et al. Large cell neuroendocrine carcinoma of the lung: a 10-year clinicopathologic retrospective study. Ann Thorac Surg. 2004;77(4):1163-1167.

25. Travis WD. Pathology and diagnosis of neuroendocrine tumors: lung neuroendocrine. Thorac Surg Clin. 2014;24(3):257-266.

26. Righi L, Volante M, Tavaglione V, et al. Somatostatin receptor tissue distribution in lung neuroendocrine tumours: a clinicopathologic and immunohistochemical study of 218 'clinically aggressive' cases. Ann Oncol. 2010;21(3):548-555.

27. Mitsudomi T, Kosaka T, Endoh H, et al. Mutations of the epidermal growth factor receptor gene predict prolonged survival after gefitinib treatment in patients with non-small-cell lung cancer with postoperative recurrence. J Clin Oncol. 2005;23(11):2513-2520.

28. Zhang Z, Stiegler AL, Boggon TJ, Kobayashi S, Halmos B. EGFRmutated lung cancer: a paradigm of molecular oncology. Oncotarget. 2010;1(7):497-514. 
29. Tam IY, Chung LP, Suen WS, et al. Distinct epidermal growth factor receptor and KRAS mutation patterns in non-small cell lung cancer patients with different tobacco exposure and clinicopathologic features. Clin Cancer Res. 2006;12(5):1647-1653.

30. Kasprzak A, Zabel M, Biczysko W. Selected markers (chromogranin A, neuron-specific enolase, synaptophysin, protein gene product 9.5) in diagnosis and prognosis of neuroendocrine pulmonary tumours. Pol J Pathol. 2007;58(1):23-33.

31. Fiala O, Pesek M, Finek J, et al. The role of neuron-specific enolase (NSE) and thymidine kinase (TK) levels in prediction of efficacy of EGFR-TKIs in patients with advanced-stage NSCLC [corrected]. Anticancer Res. 2014;34(9):5193-5198.

32. Gazdar A, Tsai C, Park J, et al. Relative chemosensitivity of non-small cell lung cancers expressing neuroendocrine properties. Proc Am Soc Clin Oncol. 1988;7:200.
33. Andoh M, Gemma A, Takenaka K, et al. Serum neuron specific enolase level as a prognostic factor in non-small cell lung cancer. Intern Med. 1994;33(5):271-276.

34. Akoun GM, Scarna HM, Milleron BJ, Bénichou MP, Herman DP. Serum neuron-specific enolase. A marker for disease extent and response to therapy for small-cell lung cancer. Chest. 1985;87(1):39-43.

35. Nojiri S, Joh T. Albumin suppresses human hepatocellular carcinoma proliferation and the cell cycle. Int J Mol Sci. 2014;15(3):5163-5174.

36. Zhang P, Zou M, Wen X, et al. Development of serum parameters panels for the early detection of pancreatic cancer. Int J Cancer. 2014;134(11) 2646-2655.

\section{Publish your work in this journal}

OncoTargets and Therapy is an international, peer-reviewed, open access journal focusing on the pathological basis of all cancers, potential targets for therapy and treatment protocols employed to improve the management of cancer patients. The journal also focuses on the impact of management programs and new therapeutic agents and protocols on

\section{Dovepress}

patient perspectives such as quality of life, adherence and satisfaction. The manuscript management system is completely online and includes a very quick and fair peer-review system, which is all easy to use. Visit http://www.dovepress.com/testimonials.php to read real quotes from published authors.

Submit your manuscript here: http://www.dovepress.com/oncotargets-and-therapy-journal 